\title{
ABORDAGEM INTEGRADA PARA AVALIAÇÃo DE ATERROS ENCERRADOS
}

INTEGRATED APPROACH FOR EVALUATING CLOSED LANDFILL SITES

Alessandro Samuel-Rosa, Ricardo Simão Diniz Dalmolin e Fabrício de Araújo Pedron

alessandrosamuel@yahoo.com.br

Universidade Federal de Santa Maria

\section{Resumo}

O descarte de resíduos sólidos urbanos (RSU) em locais inadequados é um dos principais responsáveis pela degradação ambiental. Com vistas a reverter esse quadro, o governo federal elaborou a Política Nacional de Resíduos Sólidos (PNRS). Uma ferramenta útil para atingir as metas da PNRS é o uso integrado do SAPUT (Sistema de Avaliação do Potencial de Uso Urbano das Terras) e da ClaRCA (Classificação do Risco de Contaminação Ambiental). A aplicação dessa abordagem integrada a um aterro encerrado em Santa Maria, RS, mostra que, enquanto 1) a ClaRCA define o grau de urgência na adoção de medidas de intervenção, 2) o SAPUT aponta em que direção essas medidas devem ser tomadas. No caso em estudo, foi identificado ser urgente a adoção de medidas para evitar o contato do chorume gerado pelo aterro com o aquífero e corpos d'água superficiais.

Palavras-chave: Política Nacional de Resíduos Sólidos, chorume, contaminação ambiental, remediação.

\section{Abstract}

The disposal of solid urban wastes (RSU) on inappropriate places plays an important role on environmental degradation. To reverse this 
situation, the federal government developed the National Policy on Solid Waste (NPSW). A useful tool to accomplish the NPSW goals is the integrated use of SAPUT (Evaluation System of the Urban Land Use Potential) and ClaRCA (Environmental Contamination Rating Risk). The application of this integrated approach to a closed landfill in Santa Maria, RS, Brazil, shows that while 1) ClaRCA defines the urgency degree of intervention measures adoption, 2) SAPUT points in which direction these measures must be taken. In this particular case, it was identified to be urgent the intervention measures adoption to avoid the contact of the leachate generated by the landfill with the aquifer and surface water bodies.

Key-words: National Policy on Solid Waste, leachate, environmental contamination, remediation.

\section{Introdução}

O descarte de resíduos sólidos urbanos (RSU) em locais inadequados é um dos principais responsáveis pela degradação ambiental, seja pelo volume de material disposto, seja pela presença de elementos e compostos tóxicos (Oliveira \& Pasqual, 2004; Prado Filho \& Sobreira, 2007). No Brasil, mais de $40 \%$ dos RSU gerados é descartado de maneira inadequada (lixões e aterros controlados), o que corresponde a $61 \%$ dos municípios (Abrelpe, 2010). Com isso, o chorume resultante da decomposição dos RSU pode alcançar, com facilidade, os corpos d'água, comprometendo sua qualidade. Entretanto, esse efeito poluidor poderá ser percebido somente anos ou décadas após o início do processo, já que o movimento dos poluentes no solo costuma ser lento (Guimarães, 2000).

Com vistas a reverter esse quadro, o governo federal editou, em 2010 , a Política Nacional de Resíduos Sólidos, estabelecendo diversos aspectos concernentes à disposição final ambientalmente adequada de RSU em aterros. Uma das principais etapas é a escolha do local para a instalação dos aterros, a ser definida pelos planos estaduais e municipais de RSU. Essa etapa deve englobar uma série de procedimentos, levantando informações sobre geologia, solo, relevo, clima e hidrologia. Mas, para a avaliação dessas informações, é preciso lançar mão de sistemas técnico-interpretativos. Uma das opções é o Sistema de Avaliação do Potencial de Uso Urbano das Terras (SAPUT) (Pedron, 2005), que propõe a análise e 
classificação dessas áreas, quanto a sua capacidade de suportar tal atividade sem comprometer irreversivelmente sua qualidade.

Os planos de RSU ainda devem englobar metas para implementar ações de monitoramento e recuperação de aterros encerrados (especialmente lixões). Isso é fundamental, pois, apesar dos problemas ambientais associados aos aterros encerrados (Ahmed \& Sulaiman, 2001; Rapti-Caputo, 2006; Teixeira et al., 2009; Samuel-Rosa et al., 2012), na maioria dos casos, nenhuma ou poucas práticas de remediação são adotadas, sendo escassos os esforços para reverter esse cenário. Isso ocorre em função da exigência de adoção de sistemas totalmente confinantes, que são economicamente inviáveis para a maioria dos municípios (Hamada et al., 2004). Assim, é necessário desenvolver estratégias eficientes de recuperação ambiental e monitoramento que possam ser adotadas em pequenos municípios. Métodos viáveis para classificação dos aterros de RSU quanto ao risco do chorume gerado atingir a população e os recursos naturais têm sido propostos. Exemplo disso é o método descrito por Schueler \& Mahler (2007), que sugere procedimentos de monitoramento da área de acordo com diferentes níveis de cuidado e urgência.

Métodos como aqueles propostos por Pedron (2005) e Schueler \& Mahler (2007) possuem grande potencial de uso, como ferramentas da Política Nacional de RSU. Eles permitem realizar o diagnóstico ambiental das áreas de descarte e indicar o potencial poluente dos aterros. Contudo, eles costumam ser utilizados de maneira isolada. Por esse motivo, o objetivo deste trabalho foi avaliar o uso integrado desses métodos para avaliação de aterros encerrados.

\section{Metodologia}

\section{Descrição da área}

O estudo foi desenvolvido na antiga área de descarte de RSU de Santa Maria, RS (29 $39^{\prime} 43^{\prime \prime} \mathrm{S}$; $53^{\circ} 52^{\prime} 30^{\prime \prime} \mathrm{W}$ ), localizada 7,0 km a Noroeste do centro da cidade, com uma superfície de 374.435,72 $\mathrm{m}^{2}$ e cotas altimétricas entre 76 e $98 \mathrm{~m}$. O clima é classificado como Cfa (subtropical úmido sem estação seca definida), com temperatura média anual de $19,3{ }^{\circ} \mathrm{C}$ e precipitação média anual de $1708 \mathrm{~mm}$ bem distribuídos aos longo do ano (Maluf, 2000). A unidade geológica predominante 
são arenitos e siltitos do Membro Passo das Tropas, Formação Santa Maria, uma camada permeável, com aquífero livre e confinado (Bortoluzzi, 1974). As classes de solo dominantes são Argissolos Vermelhos, nas cotas mais altas e bem drenadas, e Planossolos Háplicos, nas áreas planas e mal drenadas (Pedron et al, 2006). Os Argissolos possuem horizonte superficial (horizonte A) de granulometria grosseira e profundidade de até $75 \mathrm{~cm}$. Abaixo desse, pode ser encontrado um horizonte eluvial (horizonte E), com teor de argila ainda menor que no suprajacente. Em subsuperfície, ocorre um horizonte de textura mais fina (horizonte B), estendendo-se desde 50 até $200 \mathrm{~cm}$. Os Planossolos guardam semelhanças com os Argissolos quanto à profundidade $\mathrm{e}$ granulometria, porém com drenagem imperfeita.

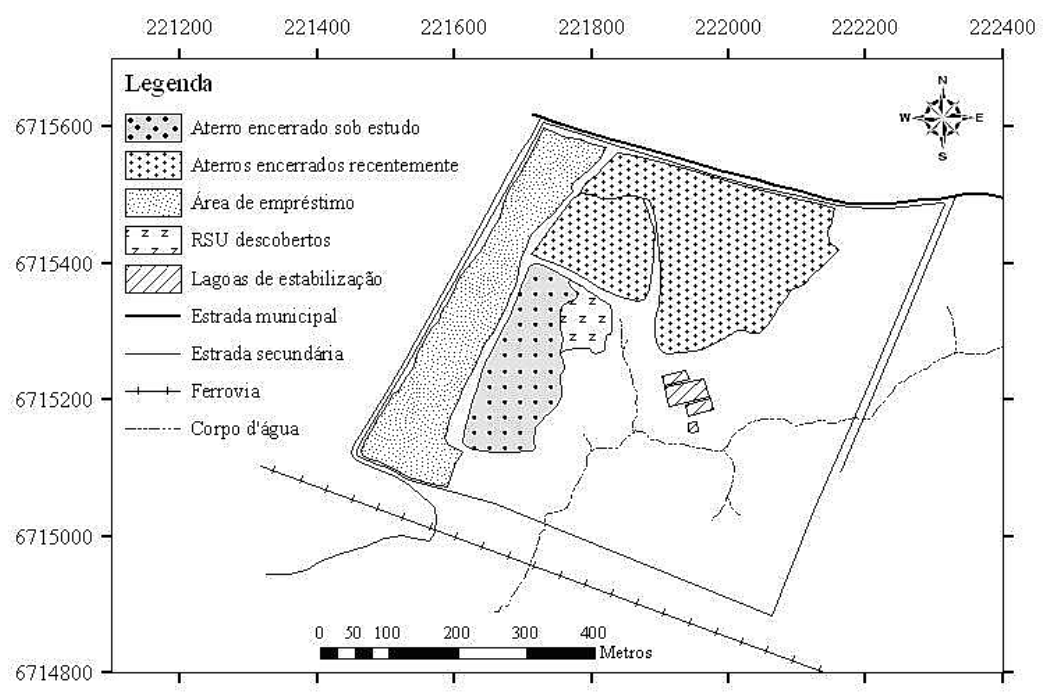

Figura 1. Antiga área de descarte de RSU de Santa Maria, RS.

No interior da área de estudo, são encontrados três aterros encerrados (dois lixões e um aterro controlado), sendo avaliado aqui o mais antigo (um lixão), que foi operado entre 1982 e meados da década de 90. Durante esse período, os RSU gerados no município eram coletados pela prefeitura municipal e depositados sobre o solo em suas condições naturais. A partir da segunda metade dos anos 90, o serviço de recolhimento de RSU foi terceirizado, quando os RSU do antigo aterro receberam uma cobertura com solo de área de empréstimo, obtido pela 
mistura do material dos horizontes A, B e C de Argissolo Vermelho, seguida da sua compactação. Atualmente, com uma superfície total de $31.813 \mathrm{~m}^{2}$ e espessura máxima da massa de RSU de $2,0 \mathrm{~m}, 82 \%$ da área permanece coberta, tendo o restante sido revolvido por catadores para coleta de materiais recicláveis. O solo construído (Samuel-Rosa et al., 2011) possui espessura de 20 a $100 \mathrm{~cm}$ e, depois de mais de 15 anos do encerramento, nenhuma intervenção para o estabelecimento de vegetação foi realizada. A montante do aterro encerrado, encontra-se a área de empréstimo, formada por uma cava em que é comum o acúmulo de água. A jusante, há uma área de inundação frequente. As demais áreas adjacentes são utilizadas com atividades agropecuárias.

\section{Diagnóstico ambiental}

O diagnóstico ambiental da área foi realizado através da avaliação do seu potencial de suportar o descarte de RSU, pela utilização do SAPUT (Pedron, 2005). Esse sistema propõe a análise e classificação de áreas urbanas quanto a sua capacidade de suportar atividades humanas e utiliza dados gerados nos levantamentos de solos, juntamente com dados dos diferentes atributos das terras, como relevo, geologia, recursos hídricos, clima e vegetação, entre outros. Nesse sistema, quatro grupos de uso urbano das terras são considerados: descarte de resíduos, construções urbanas, agricultura urbana e preservação ambiental, os quais são agrupados em três classes de uso (adequada, restrita e inadequada). Mais informações e exemplos de aplicação do SAPUT são encontrados em Pedron (2005) e Pedron et al. (2006).

\section{Classificação do risco de contaminação ambiental (ClaRCA)}

$\mathrm{O}$ aterro encerrado foi avaliado através de um sistema de classificação quanto ao risco do chorume produzido atingir a população e os recursos naturais. O objetivo do sistema é contribuir para o estabelecimento de critérios de avaliação do risco de exposição ao chorume e remediação da área, visando a sua reintegração ao ambiente (Schueler \& Mahler, 2007). O sistema é baseado na atribuição de escores a determinadas características do aterro e do ambiente circunvizinho, obtidos em matrizes divididas em função das características da fonte do contaminante (matriz 1), dos caminhos ambientais percorridos pelo contaminante (matrizes 2 e 3) e dos sujeitos potencialmente expostos (matrizes 4A e 
4B). O somatório dos escores obtidos nas matrizes [escore da matriz 1 + escore da matriz 2 + escore máximo da matriz 3 + escore máximo da matriz 4 (A e B)], fornece um indicador da necessidade, ou não, de intervenção no aterro encerrado, classificando a área em três categorias de risco de exposição ao chorume: baixo (até 20 pontos), médio (de 21 a 60 pontos) e alto (mais de 61 pontos).

\section{Resultados}

As classes de solo encontradas na área têm restrições ao descarte de RSU (Tabela 1). No Argissolo Vermelho, destacam-se como restritivos os atributos profundidade, teor de argila, CTC, distância de cursos d'água e áreas urbanas, declividade e material geológico. No Planossolo Háplico, além das anteriores (exceto declividade), destacam-se o risco de inundação, a profundidade do lençol freático e a classe de drenagem.

Os escores obtidos na ClaRCA variaram entre baixos e altos (Tabela 2). Mas o escore total está entre 61 e 100 pontos. Esse intervalo classifica o aterro como de alto risco de contaminação ambiental através do seu chorume (Schueler \& Mahler, 2007).

\section{Discussão}

O Argissolo Vermelho não apresenta potencial de suporte ao descarte de RSU, uma vez que a permeabilidade dos horizontes A e E $(1,254$ $\times 10^{-3} \mathrm{~cm} \mathrm{~s}^{-1}$ (Pinto, 2005)) está acima do limite máximo considerado pelo SAPUT. Além disso, não é recomendada a construção de aterros de RSU em áreas com predominância de solo com permeabilidade > $5 \mathrm{x}$ $10^{-4} \mathrm{~cm} \mathrm{~s}^{-1}$, mesmo sendo utilizadas impermeabilizações complementares (NBR 13.896 - ABNT, 1997). A adequação desse solo exige a adoção de procedimentos de engenharia, ou seja, remoção dos horizontes A e E, e compactação do horizonte subsuperficial (B), reduzindo sua permeabilidade para a ordem de $10^{-8} \mathrm{~cm} \mathrm{~s}^{-1}$ (Pinto, 2005).

Consideradas apenas as características intrínsecas dos solos, associadas à adoção de procedimentos de engenharia, ambas possuem potencial de suporte para descarte de RSU. Contudo, são as características ambientais que enquadram os solos como inadequados ao suporte dessas obras. A principal delas é a ocorrência de material geológico aquífero do Membro Passo das Tropas, considerado o melhor aquífero da sequência do compartimento central do sistema aquífero Guarani no 
RS (Machado, 1998). Essas áreas de recarga do aquífero exigem atenção especial e devem ser mantidas como zonas de proteção, haja vista sua vulnerabilidade à contaminação por resíduos antropogênicos. Somado a isso, a existência de nascentes e cursos de água a menos de $200 \mathrm{~m}$ do aterro e a reduzida distância de áreas urbanas torna a área inadequada para a instalação de obras de descarte de RSU. Mesmo assim, a área foi utilizada durante muitos anos para tal fim, indicando que severos danos devem ter sido causados ao ambiente.

Tabela 1. Fatores restritivos e classes de uso da terra (A - adequada; R restrita; I - inadequada) para descarte de RSU na área do aterro encerrado de Santa Maria, RS, obtidos através do SAPUT (Pedron et al., 2006).

\begin{tabular}{|c|c|c|c|c|c|}
\hline \multirow{2}{*}{\multicolumn{2}{|c|}{ Fator restritivo }} & \multicolumn{2}{|c|}{ Argissolo Vermelho } & \multicolumn{2}{|c|}{ Planossolo Háplico } \\
\hline & & Intervalo & Classe & Intervalo & Classe \\
\hline \multicolumn{2}{|c|}{ Rochosidade } & $<5 \%$ & A & $<5 \%$ & A \\
\hline \multicolumn{2}{|c|}{ Profundidade } & 1 a $2 \mathrm{~m} />2 \mathrm{~m}$ & $\mathrm{R} / \mathrm{A}$ & $1 \mathrm{a} 2 \mathrm{~m}$ & $\mathrm{R}$ \\
\hline \multirow{2}{*}{$\begin{array}{l}\text { Teor de argila } \\
\text { (horizonte) }\end{array}$} & $\begin{array}{l}\text { A e/ } \\
\text { ou E }\end{array}$ & $<25 \%$ & I & $<25 \%$ & I \\
\hline & B & 25 a $40 \%$ & $\mathrm{R}$ & $>40 \%$ & A \\
\hline \multirow{2}{*}{$\begin{array}{l}\mathrm{CTC}_{\text {potencial }} \\
\text { (horizonte) }\end{array}$} & $\begin{array}{l}\mathrm{A} \mathrm{e} / \\
\text { ou E }\end{array}$ & $<6 \mathrm{cmol}_{\mathrm{c}} \mathrm{kg}^{-1}$ & I & $\begin{array}{c}6 \text { a } 12 \mathrm{cmol}_{\mathrm{c}} \\
\mathrm{kg}^{-1}\end{array}$ & $\mathrm{R}$ \\
\hline & B & $>12 \mathrm{cmol}_{\mathrm{c}} \mathrm{kg}^{-1}$ & A & $>12 \mathrm{cmol}_{\mathrm{c}} \mathrm{kg}^{-1}$ & A \\
\hline \multirow{2}{*}{$\begin{array}{l}\text { Permeabilidade } \\
\text { (horizonte) }\end{array}$} & $\begin{array}{l}\mathrm{A} \mathrm{e} / \\
\text { ou E }\end{array}$ & $>10^{-4} \mathrm{~cm} \mathrm{~s}^{-1}$ & I & - & - \\
\hline & B & 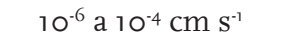 & $\mathrm{R}$ & - & - \\
\hline \multicolumn{2}{|c|}{$\begin{array}{c}\text { Distância de cursos } \\
\text { d'água }\end{array}$} & $<200 \mathrm{~m}$ & I & $<200 \mathrm{~m}$ & I \\
\hline \multicolumn{2}{|c|}{ Declividade do terreno } & o а $13 \% / 13$ a $25 \%$ & $\mathrm{~A} / \mathrm{R}$ & o a $13 \%$ & A \\
\hline \multicolumn{2}{|c|}{ Material geológico } & Aquífero & I & Aquífero & I \\
\hline \multicolumn{2}{|c|}{ Risco de inundações } & $\begin{array}{c}\text { Sem } \\
\text { inundações }\end{array}$ & A & $\begin{array}{l}\text { Inundações } \\
\text { frequentes }\end{array}$ & I \\
\hline \multicolumn{2}{|c|}{ Direção dos ventos } & - & - & - & - \\
\hline \multicolumn{2}{|c|}{$\begin{array}{c}\text { Profundidade do lençol } \\
\text { freático }\end{array}$} & $>2 \mathrm{~m}$ & A & $<1,5 \mathrm{~m}$ & I \\
\hline \multicolumn{2}{|c|}{ Tempo de descarte } & - & - & - & - \\
\hline \multicolumn{2}{|c|}{$\begin{array}{c}\text { Distância de áreas } \\
\text { urbanas }\end{array}$} & $<2 \mathrm{~km}$ & I & $<2 \mathrm{~km}$ & I \\
\hline \multicolumn{2}{|c|}{ Classe de drenagem } & Bem drenado & A & Mal drenado & $\mathrm{R}$ \\
\hline
\end{tabular}


Tabela 2. Risco do chorume produzido no aterro encerrado de Santa Maria, RS, atingir a população e os recursos naturais, conforme a ClaRCA (Schueler \& Mahler, 2007).

\begin{tabular}{|c|c|c|c|}
\hline \multicolumn{3}{|l|}{ Matriz } & \multirow[t]{2}{*}{ Escore } \\
\hline$M_{1}$ & Volume do aterro $\left(\mathrm{m}^{3}\right)$ & Idade do aterro de RSU (anos) & \\
\hline & $30.000-50.000$ & Entre 5 e 30 & 8 \\
\hline \multirow{2}{*}{ M2 } & $\begin{array}{l}\text { Camada não saturada } \\
\qquad(\mathrm{m})\end{array}$ & Permeabilidade do solo $\left(\mathrm{cm} \mathrm{s}^{-1}\right)$ & \\
\hline & 0,5 a 1,0 & $>5 \times 10^{-4}$ & 29 \\
\hline \multirow{4}{*}{$\mathrm{M}_{3}$} & Característica da área & Localização em relação ao aterro & \\
\hline & Inundável & Jusante & 18 \\
\hline & $\begin{array}{c}\text { Sujeita a escoamento de } \\
\text { alta energia }\end{array}$ & Sobre & 16 \\
\hline & Inundável & Montante & 12 \\
\hline \multirow{4}{*}{$\mathrm{M}_{4} \mathrm{a}$} & Atividade antrópica & Distância do aterro (m) & \\
\hline & Agrícola & De 101 a 200 & 17 \\
\hline & $\begin{array}{c}\text { Residencial/ parques/ } \\
\text { jardins }\end{array}$ & De 801 a 1.000 & $4(+1)$ \\
\hline & $\begin{array}{l}\text { Comercial/ industrial/ } \\
\text { serviços }\end{array}$ & $>1.000$ & ० \\
\hline \multirow{4}{*}{$\mathrm{M}_{4} \mathrm{~b}$} & Recurso natural & Distância do aterro (m) & \\
\hline & $\begin{array}{c}\text { Zonas de preservação } \\
\text { ambiental }\end{array}$ & $<100$ & 20 \\
\hline & Corpos hídricos & $<100$ & 19 \\
\hline & Zonas de proteção & De 101 a 200 & 15 \\
\hline \multicolumn{2}{|c|}{ Escore total } & & 75 \\
\hline
\end{tabular}

O baixo escore obtido na estimativa de produção de chorume (Mı) se deve ao volume e idade do aterro (entre 5 e 30 anos). Durante esse período, a velocidade de decomposição reduz gradualmente (Tchobanoglous, 1994), depois de ter alcançado um máximo ao redor de 2 a 3 anos do início da operação (Andreottola \& Cannas, 1997). O alto escore na avaliação do solo da base do aterro (M2) se deve a sua alta permeabilidade e pequena espessura da camada não saturada na porção mais baixa do 
terreno. Como o aterro foi instalado sobre o solo em suas condições naturais, sem haver qualquer intervenção para remoção ou compactação dos horizontes superficiais, todo o chorume gerado infiltra, livremente, para dentro da matriz do solo. Ao encontrar o horizonte B, mais argiloso e de menor permeabilidade, o fluxo toma um sentido horizontal, até encontrar um ponto de afloramento em superfície ou um corpo d'água. Esse efeito poluidor do chorume poderá ser percebido somente anos ou décadas após o início do processo, uma vez que seu movimento no solo costuma ser relativamente lento (Guimarães, 2000). Entretanto, segundo a autora, caso o chorume alcance a água subterrânea, ele adquire um fluxo laminar, movendo-se segundo uma corrente bem definida, chamada de pluma de contaminação, que pode vir a ser muito maior do que a área do aterro. No caso da área do aterro encerrado em estudo, a probabilidade de essa contaminação ocorrer é grande, haja vista o caráter aquífero do material geológico (Bortoluzzi, 1974).

$\mathrm{Na}$ avaliação hidrológica $\left(\mathrm{M}_{3}\right)$, a área localizada a montante do aterro foi considerada inundável, devido à cava formada para extração do material de cobertura dos RSU. Já a área do aterro foi considerada sujeita a escoamento superficial de alta energia, devido à baixa cobertura do solo (Samuel-Rosa \& Dalmolin, 2009) e elevada compactação deste. O escore retido é aquele conferido a área a jusante do aterro, cuja classe de solo ocorrente é Planossolo Háplico, característica de ambientes hidromórficos. Quanto ao sujeito potencialmente atingido (M4), ocorrem áreas de produção agrícola e zonas de preservação ambiental (nascentes) próximas do aterro, resultando em alto escore.

O escore total obtido através da ClaRCA, além de classificar o aterro como de alto risco, indica a necessidade de intervenção urgente. A recomendação é que sejam realizadas análises químicas da água subterrânea, cujos valores devem ser avaliados conforme a portaria 518 do Ministério da Saúde (Brasil, 2005). Na sequência, deve ser desenvolvido um programa de monitoramento da água subterrânea, dividido em três fases, conforme os resultados obtidos, que findará com avaliações a cada 5 anos.

Esses resultados mostram que o uso integrado da ClaRCA e do SAPUT é promissor e útil para os planos de RSU. Enquanto o ClaRCA define o grau de urgência na adoção de medidas de intervenção, o SAPUT mostra em que direção elas devem ser adotadas. No caso específico do aterro encerrado em estudo, é urgente a necessidade de adoção de medi- 
das para evitar o contato do chorume com o aquífero e os corpos d'água superficiais presentes na área. Como principal medida de recuperação, deve-se priorizar a instalação de um sistema de drenagem superficial e proporcionar o crescimento da vegetação para reduzir o escoamento superficial e infiltração da água de precipitação. A vegetação, além de impedir que toda a água precipitada chegue à superfície do solo, permitirá a sua perda para a atmosfera via evapotranspiração (Lange et al, 2006). Isso é importante porque a geração de chorume aumenta sensivelmente nos períodos chuvosos (Luz, 1981). Mas, como os corpos d'água superficiais já estão contaminados (Samuel-Rosa et al., 2012), devem ser adotadas medidas para sua remediação. A sugestão é que seja adotado o sistema de tratamento por zona de raízes, conforme descrevem Maier (2007) e Copetti (2010). Trata-se de uma técnica simples de tratamento, de fácil manutenção e de baixo custo, portanto, de fácil adoção pelos municípios de pequeno porte e/ou orçamento limitado.

\section{Conclusão}

A ClaRCA mostrou que o aterro encerrado de RSU de Santa Maria apresenta alto risco de contaminação ambiental, exigindo intervenção urgente. Já o SAPUT mostrou que a localização do aterro e a presença de material geológico aquífero subjacente potencializam esse risco de contaminação ambiental. Assim, o uso integrado dessas ferramentas permite (ClaRCA) definir o grau de urgência na adoção de medidas de intervenção e (SAPUT) mostrar em que direção essas medidas devem ser adotadas. Essa abordagem integrada permite alcançar algumas das metas da Política Nacional de RSU. No caso em estudo, a abordagem integrada mostra ser urgente a adoção de medidas para evitar o contato do chorume gerado pelo aterro com o aquífero e corpos d'água superficiais.

\section{Referências}

ABRELPE. Panorama dos resíduos sólidos no Brasil. São Paulo: Associação Brasileira de Empresas de Limpeza Pública e Resíduos Especiais, 2010. 202p.

AHMED, A.M.; SULAIMAN, W. N. Evaluation of groundwater and soil pollution in a landfill area using electrical resistivity imaging survey. Environmental Management, 28:655-663, 2001. 
ANDREOTTOLA, G.; CANNAS, P. Chemical and biological characteristics of landfill leachate. In: CHRISTENSEN, T.H.; COSSU, R.; STEGMANN, R. (Eds.) Landfilling of Waste: Leachate. Essex: Elsevier, 1992. p.65-88.

ASSOCIAÇÃO BRASILEIRA DE NORMAS TÉCNICAS - ABNT. NBR 13896: Aterros de resíduos não perigosos - critérios para projetos, implantação e operação. Rio de Janeiro, 1997.

BORTOLUZZI, C.A. Contribuição à geologia da região de Santa Maria, Rio Grande do Sul, Brasil. Pesquisas, 4:7-86, 1974.

BRASIL. Ministério da Saúde. Secretaria de Vigilância em Saúde. Coordenação-Geral de Vigilância em Saúde Ambiental. Portaria MS $\mathbf{n}^{\circ}$ 518/2004. Estabelece os procedimentos e responsabilidades relativos ao controle e vigilância da qualidade da água para consumo humano e seu padrão de potabilidade, e dá outras providências. Brasília: Editora do Ministério da Saúde, 2005. 28p.

BRASIL. Presidência da República. Casa Civil. Subchefia para Assuntos Jurídicos. Lei $\mathrm{N}^{\circ} 12.305$, de 2 de agosto de 2010 . Institui a Política Nacional de Resíduos Sólidos; altera a Lei nffl 9.605, de 12 de fevereiro de 1998; e dá outras providências. Brasília, 2010. Disponível em: < http:// www.planalto.gov.br/ccivil_03/_ato2007-2010/2010/lei/112305.htm >. Acesso em: 10 jan. 2012.

COPETTI, A.C.C. Resíduos de agroindústrias familiares: impactos na qualidade da água e tratamento com técnicas simplificadas. 139f. 2010. Dissertação (Mestrado em Ciência do Solo) - Universidade Federal de Santa Maria, Santa Maria, RS. 2010.

GUIMARÃES, L.T. Utilização do sistema de informação geográfica (SIG) para identificação de áreas potenciais para disposição de resíduos na bacia do Paquequer, município de Teresópolis - RJ. 2000. 172f. Dissertação (Mestrado em Engenharia Civil) - Universidade Federal do Rio de Janeiro, Rio de Janeiro, RJ. 2000.

HAMADA, J.; CALÇAS, D.A.N.Q.P.; GIACHETI, H. L. Influência da compactação de um solo arenoso na infiltração e retenção de carga orgânica de chorume. Engenharia Sanitária \& Ambiental, 9:180-186, 2004. 
LANGE, L.C. Processos construtivos de aterros sanitários: ênfase no estudo de camadas de cobertura como mecanismo de controle da geração de lixiviados. In: CASTILHOS Jr., A. B. de. (Ed.) Gerenciamento de resíduos sólidos urbanos com ênfase na proteção de corpos d'água: prevenção, geração e tratamento de lixiviados de aterros sanitários. Rio de Janeiro: ABES, 2006. p.109-208.

LUZ, F.X.R. Aterro sanitário: características, limitações, tecnologia para implantação e operação. São Paulo: CETESB, 1981. 30p.

MACHADO J.L.F. Hidroestratigrafia química preliminar dos aqüíferos da região central do Rio Grande do Sul. In: CONGRESSO BRASILEIRO DE ÁGUAS SUBTERRÂNEAS, 10, 1998, São Paulo. Anais... São Paulo: Associação Brasileira de Águas Subterrâneas, 1998.

MAIER, C. Qualidade de águas superficiais e tratamento de águas residuárias por meio de zonas de raízes em propriedades de agricultores familiares. 96f. 2007.

Dissertação (Mestrado em Ciência do Solo) - Universidade Federal de Santa Maria, Santa Maria, RS. 2007.

MALUF, J. A new climatic classification for the state of Rio Grande do Sul, Brazil. Revista Brasileira de Agrometeorologia, 8:141-150, 2000.

OLIVEIRA, S.; PASQUAL, A. Avaliação de parâmetros indicadores de poluição por efluente líquido de um aterro sanitário. Engenharia Sanitária \& Ambiental, 9:240-249, 2004.

PEDRON, F. de A. Classificação do potencial de uso das terras no perímetro urbano de Santa Maria - RS. 2005. 74f. Dissertação (Mestrado em Ciência do Solo) - Universidade Federal de Santa Maria, Santa Maria, 2005.

PEDRON, F.A.; DALMOLIN, R.S.D.; AZEVEDO, A.C.; POELKING, E.L.; MIGUEL, P.Utilização do sistema de avaliação do potencial de uso urbano das terras no diagnóstico ambiental do município de Santa Maria - RS. Ciência Rural, 36:468-477, 2006. 
PINTO, J.S. Estudo da condutividade hidráulica de solos para disposição de resíduos sólidos na região de Santa Maria. 2005. 154f. Dissertação (Mestrado em Engenharia Civil) - Universidade Federal de Santa Maria, Santa Maria, 2005.

PRADO FILHO, J.; SOBREIRA, F. Desempenho operacional e ambiental de unidades de reciclagem e disposição final de resíduos sólidos domésticos financiados pelo ICMS ecológico de Minas Gerais. Engenharia Sanitária \& Ambiental, 12:52-61, 2007.

RAPTI-CAPUTO, D.; SDAO, F.; MASI, S. Pollution risk assessment based on hydrogeological data and management of solid waste landfills. Engineering Geology, 85:122-131, 2006.

SAMUEL-ROSA, A.; DALMOLIN, R.S.D. Fauna edáfica em solo construído, campo nativo e lavoura anual. Ciência Rural, 39:913-917, 2009.

SAMUEL-ROSA, A.; DALMOLIN, R.S.D.; COPETTI, A.C.C. A poluição causada por aterros de resíduos sólidos urbanos sobre os recursos hídricos. Ciência e Natura, 34:107-118, 2012. (in press)

SAMUEL-ROSA, A.; DALMOLIN, R.S.D.; PEDRON, F.A. Characterization of soil covers in closed landfill sites with (geo)statistical tools. Engenharia Sanitaria e Ambiental, 16:121-126, 2011.

SCHUELER, A.; MAHLER, C. Sistema de avaliação para classificar áreas de disposição de resíduos sólidos urbanos visando a remediação e a pós-ocupação. Engenharia Sanitária \& Ambiental, 13:249-254, 2007.

TCHOBANOGLOUS, G., THEISEN, H.; VIGIL, S. Gestión integral dos residuos sólidos. 1.ed. Madri: McGraw-Hill Inc, 1994. 1106p.

TEIXEIRA, C.E.; TORVES, J.C.; FINOTTI, A.R.; FEDRIZZI, F.; MARINHO, F.A.M.; TEIXEIRA, P.F. Estudos sobre a oxidação aeróbia do metano na cobertura de três aterros sanitários no Brasil. Engenharia Sanitária \& Ambiental, 14:99-108, 2009.

Submetido em: 24/02/2011

Aceito em: 23/11/2012 
